\title{
Effects of Physical Fitness and Mental Hardness on the Performance of Elite Male Basketball Players
}

\author{
Sertaç Erciş \\ Correspondence: Sertaç Erciş, Faculty of Sport Sciences, Ataturk University, Erzurum, Turkey.
}

Received: July 11, 2018

doi:10.11114/jets.v6i9a.3526
Online Published: August 6, 2018

URL: https://doi.org/10.11114/jets.v6i9a.3526

\begin{abstract}
The purpose of this study was to study the effects of physical fitness and mental hardness on the performance of elite basketball players in Turkey. The research included a population of 80 elite male athletes, and the size of the population and the sample size were equal and the method of selection was purposeful one. The instruments consisted of physical fitness measurements. Goldberg General Health Questionnaire and hardiness questionnaire with components of challenge, control, trust, excitement, self-confidence and commitment with the reliability of 0.88 and the exercise performance questionnaire were used to evaluate the performance and practice variables with a reliability of 0.82 which all of them were more than 0.78 in the preliminary design. Pearson correlation analysis and structural equations were used to answer the hypotheses. Physical fitness had affected psychological characteristics and performance. Since their importance is clear to everybody, we need to plan to enhance their psychological and mental health.
\end{abstract}

Keywords: physical fitness, mental hardiness, elite basketball athletes

\section{Introduction}

Today, progressive mental illness and mental disorders are one of the main causes of people's disability (Engin, 2009). In fact, one's ability to perform physical activity from muscular effort is called physical fitness or a set of features Intrinsic and acquired, which is the ability to perform physical activity. Therefore, individuals can exercise physical fitness in relation to muscle strength, muscular strength, muscular endurance, cardio respiratory endurance, flexibility, physical fitness, and agility (Thompson, 2017).

Shelangoski and Hamberick (2014) showed that their experiences and their sports history and the suitability of the training conditions and the gender effect of the manhood had a significant relationship with the desired level of selfesteem training, physical fitness, and their performance. Given the great impact of physical fitness exercises on psychological characteristics, special attention is required to performance of athletes.

In fact, sport as a multidimensional instrument with a vast impact and valuable role, is one way in which individuals can help with physical, emotional, psychological and social pressures. Several studies have made it clear that addressing healthy recreational activities, especially sports activities have many positive effects on human physical and mental health. Newland et al. (2013) argued that physical activity has a continuing impact on the health of individuals and their mental health. According to the WHO (2011), mental health is the perfection of physical, psychological and social wellbeing, and not just the absence of diseases. For this organization, mental well-being, prevention of mental illness, and the treatment and rehabilitation of people suffering from mental problems also include mental health.

Mental health is the ability to communicate with individuals, modify the individual and social environment, and solve conflicts and personal preferences logically, fairly and proportionally. Mental health refers to the health of thought and is intended to indicate the positive state and mental health and ways to achieve it, which has a role in the balance of the self and the community (Newland, 2013). Also, Hystad (2012) says: Mental health is the person's adaptation to the environment with the maximum possible, trying to be happy, so that happiness leads to salvation. Psychological health is one of the important factors in the life of individuals and organizations, mental health and Mindfulness along the side leads to the empowerment of human resources.

In fact, mental hardiness is one of the characteristics of personality. The tenacity of a set consists of a personality trait that acts as a source of resistance as a protective shield in the face of stressful life events. Stiff people often find life events interesting, diverse, informative and challenging. They consider life events as realistic or with a long-term vision, and are therefore more optimistic about the whole of life's events. Perhaps there is the same optimism that makes 
the hardline people out of unpleasant incidents, and so on, expecting more illnesses. They consider life events as realistic or with a long-term vision, and for this reason, relative to all life events are more optimistic. Perhaps there is the same optimism that has made the hard-line people out of unpleasant incidents, and so on and more susceptible to disease (Cash et al., 2011). Basketball is considered today as a popular sport with a showcase and it is a good idea to see the progress of the day with its optimal performance. Therefore, in order to achieve the optimal development of the attention of the supporters, coaches and the basketball federation, this study needs to be done and, given the serious efforts of the officials Related to sport and attention to physical fitness factors such as endurance, strength, flexibility, ability, speed, physical composition and psychological characteristics of mental health and psychological difficulty, as well as high emphasis on policy related to the development, function and function, development and Expansion of Basketball Bash The important question is that "the effects of physical fitness and psychological characteristics (mental hardiness, mental health) on the performance of elite basketball players in the country.

Newland et al. (2013) found that among the firefighters, in addition to maintaining health, muscular analysis and heart disease, there were significant points, and there was a significant relationship between marital status and body mass. Hystad et al. (2012) confirmed the factors of tenacity by factor analysis and their meaningful positive relationships among male employees. Garriguet et al. (2015) did not measure the strength and speed of cardiovascular function of adult Canadian people in a favorable situation. Rice et al (2016) have had high levels of exercise and training, or various sports injuries, or even burns. Competitive conditions, stress to overcome challenges and optimal performance of sport have a negative effect on mental health of elite athletes. Lin et al. (2017) showed that personality traits lead to the use of problem-solving strategies, hardiness and mental health, and hardiness is a good predictor of mental health and performance.

\section{Method}

The type of research is descriptive-correlation and in terms of its purpose and time dimension. The present study is looking for factors of physical and mental fitness, mental health and its effect on the performance of elite basketball players.

The research community is active in all players of elite basketball players, which is 80 athletes.

In this research, three different instruments were used for measuring physical fitness, the Goldberg General Health Questionnaire, and Hardiness Questionnaire and Sports Performance Questionnaire.

\subsection{Physical Fitness Biomechanical Parameters Measurement Tool}

\section{-Stopwatch}

-Test 10 and 40 meters

-bar test

\subsection{Physiological Parameter Measurement Tool}

- Layout test in 60 seconds

- Two $4 * 9$

- Test 540

\subsection{Data Collection Instruments}

Goldberg Mental Health Scale: This questionnaire was developed by Goldberg (1972) to identify mental disorder psychosis, which "was widely used to diagnose mild psychological disorders and screening psychiatric disorders (non psychotic disorder) in health centers and other communities in different situations ". The 28 -item form has 4 scales, each of which contains 7 questions.

Scales include: 1) physical syndrome, 2) anxiety and sleep disorders, 3) social function disorder, 4) severe depression and suicidal tendency. The subject's response to each question is in a four-point range. Gold leaf (1980) correlated the GHQ scores and the clinical outcome of the severity of the disorder by $80 \%$.

Hardness Scale: It is a Self-Reporting Scale that has 27 items. The scoring of this questionnaire in Article 27 is that the subjects responded to one of the four "never," "rarely" "sometimes," "most often" and based on values $0,1,2,3$ They are scored, with the exception of materials $6,7,10,13,17,21$, which have a negative factor load and are graded in reverse manner. The score range in this questionnaire is from 0 to 81 . The high score in this questionnaire shows a high psychological hardiness in a person.

Athletic Performance Questionnaire: This questionnaire was developed by Ralph Pidmont in 1997, and each player is trained by Sherman and Assistant Coach in five dimensions of performance that includes (tactics, athletic skills, 
performance in the game, teamwork, work ethic). The questionnaire is a seven-point Likert scale, with 1 completely weak and 7 quite strong.

\subsection{Data Analysis}

In the scope of the test, multiple regressions were used.

\section{Results}

Table 1. The age of participants

\begin{tabular}{ccc}
\hline Age & $\mathrm{F}$ & $\%$ \\
\hline Less than 18 & 17 & 31 \\
$18-22$ & 23 & 42 \\
$23-27$ & 8 & 14.55 \\
$28-32$ & 7 & 12.45 \\
Total & 55 & 100 \\
\hline
\end{tabular}

As table 1 shows, $42 \%$ of athlete are between $23-27$ and $12.45 \%$ are between $28-32$ years old.

Table 2. Results of physical fitness with mental hardiness and its components in elite basketball

\begin{tabular}{lccccccc} 
Physical fitness & $\begin{array}{c}\text { Mental } \\
\text { Hardness }\end{array}$ & $\begin{array}{c}\text { Mentally } \\
\text { Trust }\end{array}$ & $\begin{array}{c}\text { Individual } \\
\text { trust }\end{array}$ & $\begin{array}{c}\text { Life } \\
\text { control }\end{array}$ & $\begin{array}{c}\text { Excitement } \\
\text { control }\end{array}$ & Commitment & Challenge \\
\hline $\mathrm{r}$ & $0.193^{*}$ & 0.070 & $0.211^{*}$ & 0.079 & 0.140 & 0.176 & 0.165 \\
\hline Sig. & 0.038 & 0.440 & 0.020 & 0.398 & 0.135 & 0.052 & 0.069 \\
\hline
\end{tabular}

According to the table, there is a relatively weak and significant correlation between physical fitness and mental retardation variables $(\mathrm{Sig}=0.05)$. In other words, with the increase in physical fitness, the hardiness of their subjects increases. The results also showed that physical fitness is only correlated with self-confidence component and with other components there is no statistically significant correlation.

Table 3. Result of physical fitness with mental health and its components in elite basketball

\begin{tabular}{lccc}
$\begin{array}{l}\text { Variable } \\
\text { Physical fitness }\end{array}$ & Psychological well-being & $\begin{array}{c}\text { Signs of positive mental } \\
\text { health }\end{array}$ & $\begin{array}{c}\text { symptoms of mental } \\
\text { disorders }\end{array}$ \\
\hline r & -0.101 & -0.069 & -0.101 \\
\hline Sig. & 0.276 & 0.405 & 0.235 \\
\hline
\end{tabular}

According to the above table, there is no significant correlation between physical fitness and mental health variable (Sig $\geq 0.05$ ).

Table 4. Result of physical fitness with Sport, training and match performance

\begin{tabular}{lccc}
\hline & Sport performance & Training performance & Match performance \\
Variable & & & \\
\hline $\mathrm{r}$ & $0.304^{* *}$ & $0.208^{*}$ & $0.248^{* *}$ \\
\hline Sig. & 0.001 & 0.014 & 0.007 \\
\hline
\end{tabular}

Regarding the table between physical fitness and exercise performance variables, there is a direct, relatively weak and significant correlation $(\mathrm{Sig}=0.05)$. In other words, with the increase in physical fitness of individuals, their performance increases.

\section{Discussion and conclusion}

Estimated values indicate that there is a direct, relatively weak and significant correlation between physical fitness and mental retardation variables $(\mathrm{Sig}=0.05)$. In other words, with the increase in physical fitness, the hardiness of their subjects increases. The results also showed that physical fitness is only correlated with self-confidence component and with other components there is no statistically significant correlation. Lin et al. (2017) reviewed the impact of psychological hardiness and individual differences, work performance, and happiness. The results indicate that it would increase the performance of sporting activities.

Hystad et al. (2012) found there is no significant difference between the three subscales of reliability, stability and control. Findings show that there is a meaningful relationship between endurance of shoulder muscle, leg muscle strength, aerobic endurance, general physical fitness and reliability subscale. Also, the correlation between aerobic endurance and control subscale is significant, but no significant relationship was found between the total mental hardiness score and none of the physical fitness indices. 
The research findings suggest that combination of physical and psychological features would bring athletes to the peak of performance.

Athletes, in particular, elite athletes, are usually well-equipped to compete in the best possible scores. Because having physical fitness and optimal conditions requires hard training and multiple tests, the athlete should be psychologically well-optimized. So that he can work with patience and patience that a person has a commitment to his practice and medal, he has the control of excitement and challenge, trust in his training and his duty as a national captain is what is referred to as stubbornness.

In fact, performing high-level fitness exercises for the players in the Basketball League requires toughness. If the level of physical fitness is low, it will lead to toughness. The present study is in line with the researches of Hardy (2014) and Lin et al. (2017).

Estimated values in the table above indicate that there is no significant correlation between physical fitness and mental health variable ( $\mathrm{Sig}=0.05$ ). Rice et al (2016) found that there was a lot of exercise and training, or various sports injuries, or even anorexia, that the patients were unsuccessful. No mental health has resulted in the lack of happiness and even athletic addiction. Conditions Strengths of competitions, stress, overcoming challenges, and athletic performance have also had a negative effect on the mental health of elite athletes.

Lin et al. (2017) showed that hardness and mental affinity are correlated. Hardness is a good predictor of mental health. Physical fitness, its factors including agility, speed, power, power, flexibility, etc., and generally sport, lead to mental health and mental health of individuals, exercise leads to anxiety, depression and diseases different, and other benefits are clear to everyone.

The present study did not indicate this relationship. It may be that there is a lack of correlation with the intense physical fitness training that exists between the nationalists or competitive anxiety, the tension of the spectators, and other factors that lead to a reduction in mental health.

Therefore, we need to further explore and identify the factors that reduce the mental health of athletes. Perhaps the sampling error led to the creation of this non-relationship. The research is consistent with Rice's (2017), Lin (2017) research.

Results show that there is a direct, relatively weak and significant correlation between physical fitness and exercise performance variables $(\mathrm{Sig}=0.05)$. In other words, with the increase in physical fitness of individuals, their performance increases. Perroni et al. (2013) found a significant relationship with the performance of the Italian firefighters, which was aimed at developing and maintaining tests. Shelangoski \& Hambrick (2014) shows the experiences and years of participation in the sport and the suitability of the conditions of exercise and the level of physical fitness will lead to the occupational effectiveness of individuals.

The athletic performance of individuals derives from physical, psychological or external factors. When a person has a high level of physical fitness, these physical factors, especially for a basketball player, will be optimized in a competitive environment. The athletic performance of individuals derives from physical, psychological or external factors. When a person has a high level of physical fitness, these physical factors, especially for a basketball player, will be optimized in a competitive environment. Suitable speed, high agility, reaction time, nerve coordination, and all-in-one psychosocial skills are the competitor's points of view. For each level of physical fitness, there is a better chance of competition. The current study is in line with Cash \& Gardner et al (2011), Shelangoski \& Hambrick (2014).

Thomson (2017) states that elite rugby players will increase their hardiness, their performance will increase. Also, stress control has increased stiffness and performance Lin et al. (2017) has shown that the stress level, depression and anxiety of individuals' decreases with increasing their hardiness. Due to the increasing severity of their mental health, their hardiness levels are close to their level of physical fitness. The research is consistent with Thompson (2017).

Russell (2014) examines the students' physical fitness, and their condition is desirable. Gargogit (2015), as a tool for measuring physical activity, did not measure the physical fitness of Canadian adults. They did not measure their strength and speed and their cardiovascular ability in the optimum situation. The performance of the organization was optimally located. The present study with the research of Garriguet et al. (2015), Russell (2014) is consistent.

\section{References}

Cash, M. L., \& Gardner, D. (2011). Cognitive hardiness, appraisal and coping: Comparing two transactional models. Journal of Managerial Psychology, 26(3), 487-507. https://doi.org/10.1108/02683941111181752

Garriguet, D., Tremblay, S., \& Rachel, C. (2015). Comparison of Physical Activity Adult Questionnaire results with data Health Statistics Canada, Health Reports, 26(7), 11-17. 
Hystad, S. W., Eid, J., \& Brevik, J. I. (2012). Effects of psychological hardiness, job demands, and job control on sickness absence: A prospective study. Journal of Occupational Health Psychology, 16, 487-507.

Lin, Y., Mutz, J., Clough, P. J., \& Papageorgiou, K. A. (2017). Mental Toughness and individual differences in learning, educational and work performance, psychological well-being, and personality: A systematic review. Frontiers in Psychology. https://doi.org/10.3389/fpsyg.2017.01345

MacNamara, Á., Button, A., \& Collins, D. (2010). The role of psychological characteristics in facilitating the pathway to elite performance. Part 1: Identifying mental skills and behaviours. The Sport Psychologist, 24(1), 52-73. https://doi.org/10.1123/tsp.24.1.52

Newland, A., Newton, M., Finch, L., Harbke, C. R., \& Podlog, L. (2013). Moderating variables in the relationship between mental toughness and performance in basketball. Journal of Sport and Health Science, 2(3), 184-192. https://doi.org/10.1016/j.jshs.2012.09.002

Rice, V. S. M., Rosemary, P., \& Stefanie, D. (2016). The Mental Health of Elite Athletes: A Narrative Systematic Review, Sports Med., 46, 1333-1353. https://doi.org/10.1007/s40279-016-0492-2

Russell, R., \& Jennifer, R. (2014). Physical Activity in Preschool Children: Comparison Between Montessori and Traditional Preschools, Journal of School Health, 84(11), 421-430.

Shelangoski, B. L., \& Hambrick, M. E. (2014). Self-Efficacy in Intercollegiate Athletes. Journal of Issues in Intercollegiate Athletics, 7, 17-42.

Thompson, C. (2017). Improving Hardiness in Elite Rugby Players, Thesis Submitted in Partial Fulfillment of the Requirements for the Degree of Doctor of Applied Psychology (Sport)

\section{Copyrights}

Copyright for this article is retained by the author(s), with first publication rights granted to the journal.

This is an open-access article distributed under the terms and conditions of the Creative Commons Attribution license which permits unrestricted use, distribution, and reproduction in any medium, provided the original work is properly cited. 